\title{
Folate-Targeted Gadolinium-Lipid-Based Nanoparticles as a Bimodal Contrast Agent for Tumor Fluorescent and Magnetic Resonance Imaging
}

\author{
Taro Nakamura, ${ }^{a}$ Kumi Kawano, ${ }^{*, a}$ Kouichi Shiraishi, ${ }^{b}$ Masayuki Yokoyama, ${ }^{b}$ and \\ Yoshie Maitani ${ }^{a}$ \\ ${ }^{a}$ Institute of Medicinal Chemistry, Hoshi University; 2-4-41, Ebara, Shinagawa-ku, Tokyo 142-8501, Japan: and \\ ${ }^{b}$ Medical Engineering Laboratory, Research Center for Medical Science, The Jikei University School of Medicine; \\ 3-25-8, Nishi-shinbashi, Minato-ku, Tokyo 105-8461, Japan.
}

Received June 15, 2013; accepted January 15, 2014

\begin{abstract}
To enhance tumor magnetic resonance imaging (MRI) signals via the selective accumulation of contrast agents, we prepared folate-modified gadolinium-lipid-based nanoparticles as MRI contrast agents. Folatemodified nanoparticles were comprised of polyethylene glycol (PEG)-lipid, gadolinium diethylenetriamine pentaacetic acid lipid, cationic cholesterol derivatives, folate-conjugated PEG-lipid, and Cy7-PEG-lipid. Folate receptor-mediated cellular nanoparticle association was examined in KB cells, which overexpress the folate receptor. The biodistribution of nanoparticles after their intravenous injection into KB tumor-bearing mice was measured. Mice were imaged through in vivo fluorescence imaging and MRI $24 \mathrm{~h}$ after nanoparticle injection, and the intensity enhancement of the tumor MRI signal was evaluated. Increased cellular association of folate-modified nanoparticles was inhibited by excess free folic acid, indicating that nanoparticle association was folate receptor-mediated. Irrespective of folate modification, the amount of nanoparticles in blood $24 \mathrm{~h}$ after injection was $c a .10 \%$ of the injected dose. Compared with non-modified nanoparticles, folate-modified nanoparticles exhibited significant accumulation in tumor tissues without altering other biodistribution, as well as enhanced tumor fluorescence and MRI signal intensity. The results support the feasibility of MRI- and in vivo fluorescence imaging-based tumor visualization using folate-modified nanoparticles and provide opportunities to develop folate targeting-based imaging applications.
\end{abstract}

Key words folate modification; tumor imaging; lipid-based nanoparticle; magnetic resonance imaging (MRI) contrast agent; KB tumor

Magnetic resonance imaging (MRI) is a non-invasive method for tumor detection that provides high-resolution images of anatomical structures. The use of gadolinium (Gd)-based MRI contrast agents shortens the longitudinal relaxation times $\left(T_{1}\right)$ of water proton, resulting in signal enhancement of $T_{1}$-weighted images, and improves the detection of the morphological and functional abnormalities of tumors. The usefulness of small molecular contrast agents in clinical practice is limited by low specificity for the intended target tissues, and need to use high concentrations, for signal enhancement. To overcome these shortcomings, a wide variety of macromolecules and nanoparticulate systems have been developed as Gd-based MRI contrast agents, including proteins, ${ }^{1)}$ dendrimers,${ }^{2)}$ polymers, ${ }^{3-5)}$ liposomes, ${ }^{6-8)}$ and micelles. ${ }^{9-11)}$ Since nano-sized carrier systems passively extravasate from the circulation through the vascular gaps of the tumor neovasculature, a process termed the enhanced permeability and retention (EPR) effect, ${ }^{12)}$ they have been utilized for the delivery of contrast agents and therapeutic agents to tumors. ${ }^{11,13)}$

To increase tumor selectivity, these imaging systems were modified with ligands that specifically interact with tumor tissues. ${ }^{14-17)}$ The folate receptor is a promising target for tumorspecific contrast agents because of its overexpression in many types of human tumors and its relative absence in most normal tissues. ${ }^{18,19)}$ Folate receptor-mediated MRI contrast agents such as folate-modified Gd-chelates, ${ }^{20)}$ Gd-conjugated dendrimers, ${ }^{21,22)}$ folate-modified iron oxide nanoparticles, ${ }^{23-25)}$ and folate-modified lipid based nanocarriers such as liposomes ${ }^{26}$ ) have been investigated. In the case of antitumor drug deliv-

The authors declare no conflict of interest ery, folate-modified lipidic nanocarriers increased the tumor accumulation and enhanced the antitumor effect of drugs against folate receptor-overexpressing tumors, although it was clarified that the advantage of increased targeting by folate modification is obscured by the accelerated clearance of ligand-modified formulations. ${ }^{27-29)}$ Therefore, prolonged circulation in blood is key for the tumor targeting of folate-modified nanocarriers. Polyethylene glycol (PEG)-lipid micelles possess several properties that make them promising carriers of contrast agents; their surface protection by PEG chains reduces their clearance from blood and they can be easily modified with a wide range of ligands or incorporate several imaging probes for multimodality imaging. ${ }^{30-32)}$ Moreover, the addition of cholesterol to PEG-lipid micelles reduced core lipid mobility, resulting in enhanced micellar stability of the PEG-lipid micelles. ${ }^{33)}$

In this study, in order to attenuate the accelerated clearance by folate modifications and improve the targeting efficiency, we prepared nanoparticulate contrast agent by the addition of cationic cholesterol derivatives to PEG-lipid micelles. The biodistribution of nanoparticles was evaluated in folate receptor-overexpressing tumor-bearing mice by evaluating the $\mathrm{Gd}$ amount, in vivo fluorescence imaging and MRI.

\section{MATERIALS AND METHODS}

Materials Gd-diethylenetriamine pentaacetic acid-bisstearylamide (Gd-DTPA-bis-stearylamide) was purchased from Chemir Analytical Services (Maryland Heights, MO, U.S.A.). Cholesteryl $3 \beta-N$-(dimethylaminoethyl)carbamate hydrochloride (DC-Chol) was purchased from Sigma-Aldrich 
Japan, (Tokyo, Japan). Methoxy-PEG-distearoylphosphatidylethanolamine (PEG mean molecular weight of 2000, $\mathrm{PEG}_{2000^{-}}$ DSPE) and amino-PEG-DSPE (PEG mean molecular weights of 2000 and 5000) were purchased from NOF Corporation (Tokyo, Japan). Folate-linked $\mathrm{PEG}_{2000^{-}} \mathrm{DSPE}$ (folate- $\mathrm{PEG}_{2000^{-}}$ DSPE) and folate-PEG ${ }_{5000}-\mathrm{DSPE}$, which are conjugates of folic acid and amino-PEG-DSPE, were prepared as reported previously. ${ }^{28,34)}$ Cy7 NHS ester was purchased from GE Healthcare (Bucks, United Kingdom), and Cy7-labeled PEG $_{2000}$-DSPE was prepared from amino- $\mathrm{PEG}_{2000}$-DSPE according to the manufacturer's instruction. All other chemicals were of reagent grade.

Preparation of Nanoparticles The preparation of MRI contrast agents composed of Gd-DTPA-bis-stearylamide and $\mathrm{PEG}_{2000}$-DSPE followed the protocol of Beilvert et al. ${ }^{35)}$ with some modifications. In brief, unmodified nanoparticles (NPs) were prepared from Gd-DTPA-bis-stearylamide/ $\mathrm{PEG}_{2000^{-}}$ DSPE/DC-Chol (41.7/41.7/16.6, molar ratio). Folate-modified NPs (F(2000 or 5000)-NP) were prepared via the addition of F-PEG 2000 -DSPE or F-PEG ${ }_{5000}$-DSPE to PEG-DSPE NPs (GdDTPA-bis-stearylamide/PEG 2000 -DSPE/DC-Chol/F-PEG-DSPE (41.7/41.3/16.6/0.4, molar ratio). The folate modification density, $0.4 \mathrm{~mol} \%$, referred to that of folate-modified liposomes. ${ }^{29,36)}$ Cy7-labeled NPs were prepared via the addition of $0.01 \mathrm{~mol} \%$ Cy7-PEG ${ }_{2000}$-DSPE to NPs or F-NPs. The lipids were dissolved in chloroform-methanol 4:1 (v/v). A thin film was obtained by gradually removing the solvents under vacuum at $65^{\circ} \mathrm{C}$. The film was hydrated by phosphate-buffered saline (PBS, pH 7.4) at $70^{\circ} \mathrm{C}$ and stirred until a clear suspension was formed.

Characterization of Nanoparticles The particle size and $\zeta$-potential of the NPs was determined at $25^{\circ} \mathrm{C}$ in 10 -fold-diluted PBS using a dynamic and electrophoretic light scattering method with an ELS-Z2 instrument (Otsuka Electronics Co., Ltd., Osaka, Japan). The Gd concentration was determined using inductively coupled plasma (ICP) with an SPS7800 apparatus (SII NanoTechnology Inc., Tokyo, Japan). The Gd loading efficiency was calculated by comparing the amount of Gd before and after dialysis (SpectraPor, U.S.A., MWCO 2000) against PBS for $24 \mathrm{~h}$. To evaluate the function of the MRI contrast agent, the $T_{1}$ values of NP suspensions were measured by means of the inversion recovery method over the concentration range of $0-1.0 \mathrm{~mm}$ Gd at $9.4 \mathrm{~T}$ (Varian NMR system, Varian, Palo Alto, CA, U.S.A.) at room temperature. Longitudinal relaxivity $\left(R_{1}\right)$ was calculated from the slope of the linear regression fits of $1 / T_{1} v s$. the Gd concentration ([Gd]) by using the following equation: $1 / T_{1}=R_{1} \times[\mathrm{Gd}]+1 / T_{10}$, where $T_{10}$ represents $T_{1}$ of $0 \mathrm{~mm}$ Gd solution (PBS).

Cell Culture A human nasopharyngeal cell line, KB, was supplied by the Cell Resource Center for Biomedical Research, Tohoku University (Miyagi, Japan). The cells were cultured in folate-deficient RPMI 1640 with $10 \%$ heat-inactivated fetal bovine serum (Invitrogen Corp., Carlsbad, CA, U.S.A.) and $100 \mu \mathrm{g} / \mathrm{mL}$ kanamycin sulfate (Wako Pure Chemical Industries, Ltd., Osaka, Japan) with $5 \% \mathrm{CO}_{2}$ at $37^{\circ} \mathrm{C}$.

Cellular Association of Gd Assessed by ICP KB cells were incubated with NPs or folate-modified NPs suspended in serum-free, folate-deficient medium at $20 \mu \mathrm{g}$ total lipids $/ \mathrm{mL}$ for $1 \mathrm{~h}$ at $37^{\circ} \mathrm{C}$. In free folate competition studies, $2 \mathrm{mmol} / \mathrm{L}$ folic acid was added to the medium. After incubation, cells were washed thrice with PBS ( $\mathrm{pH}$ 7.4) to remove unbound
NPs and then lysed with PBS containing $0.5 \%$ Triton-X100, followed by centrifugation. The supernatant was applied to ICP measurements for Gd content determination.

Animals and Tumor Inoculation Specific pathogen-free female athymic BALB/c nu/nu mice (5 weeks of age on arrival, CLEA Japan, Inc., Tokyo, Japan) were maintained on a folate-deficient rodent diet (Oriental Yeast Co., Ltd., Tokyo, Japan) on arrival and for the duration of the study. To generate tumor xenografts, $1 \times 10^{7} \mathrm{~KB}$ cells suspended in PBS were injected subcutaneously into the right flank region of the mice. Intravenous injection of the contrast agents was started $14 \mathrm{~d}$ after the cell inoculation. The animal experiments were conducted under ethical approval from the Committee on Animal Research of our institute.

Blood Gd Concentration in Mice The NPs were injected intravenously into $\mathrm{BALB} / \mathrm{c}$ nude mice at a dose of $0.2 \mathrm{mmol}$ $\mathrm{Gd} / \mathrm{kg}$. Blood was collected from the tail vein using heparinized glass capillary tubes. Saline was added to the blood, and the mixture was centrifuged at $4^{\circ} \mathrm{C}$ for $4 \mathrm{~min}$ at $15000 \mathrm{rpm}$. The supernatant of the plasma solution was collected, and the Gd content of the NPs was measured using ICP. The plasma volume was calculated as $48.8 \mathrm{~mL} / \mathrm{kg}$ body weight.

Biodistribution Studies in Tumor-Bearing Mice The biodistribution of the NPs was evaluated in KB tumor-bearing mice. At $24 \mathrm{~h}$ after the injection of NPs at a dose of $0.2 \mathrm{mmol}$ $\mathrm{Gd} / \mathrm{kg}$, the major tissues including tumor tissues were excised and weighted. For the determination of Gd content in the tissues, nitric acid (conc. 70\%) and sulfuric acid (conc. 98\%) were added to the tissues, and the mixtures were heated. A saturated aqueous ammonium oxalate solution was added to the yellow mixture, which was heated again. The resulting pale yellow mixture was diluted with ultrapure water. After filtration, the Gd content of the solution was measured using ICP.

Near-Infrared Fluorescence Imaging of Tumor-Bearing Mice The surface fluorescence intensity of mice bearing KB tumors was imaged at 6 and $24 \mathrm{~h}$ after intravenous injection of the NPs at a dose of $0.2 \mathrm{mmol} \mathrm{Gd} / \mathrm{kg}$ by using in vivo near-infrared fluorescence imaging with a NightOWL LB981 NC100 system (Berthold Technologies, Bad Wildbad, Germany) with a Cy7 filter set (excitation: 680/30 nm; emission: 775/30 nm). All fluorescence images were acquired with a 10-s exposure, and regions of interest were drawn over the tumors.

MRI of Tumor-Bearing Mice MR images were taken with a Varian NMR system at 9.4T. $T_{1}$-Weighted gradient echo images were acquired before and $24 \mathrm{~h}$ after intravenous injection of the NPs at a dose of $0.2 \mathrm{mmol} \mathrm{Gd} / \mathrm{kg}$ into mice bearing KB tumors. The imaging parameters of the $T_{1}$-weighted images were as follows: for a coronal slice: $\mathrm{TR}=$ $10.0 \mathrm{~ms}, \mathrm{TE}=5.5 \mathrm{~ms}$, flip angle $=30^{\circ}$, field of view $=50 \times 30 \mathrm{~mm}$, a matrix size $=256 \times 256$, and thickness $=2 \mathrm{~mm}$; for an axial slice: $\mathrm{TR}=15.0 \mathrm{~ms}, \mathrm{TE}=5.0 \mathrm{~ms}$, flip angle $=30^{\circ}$, field of view $=$ $45 \times 45 \mathrm{~mm}$, a matrix size $=128 \times 128$, and thickness $=2 \mathrm{~mm}$. The signal intensity of the tumor area was normalized using the intensity of agarose gel containing $0.1 \mathrm{~mm}$ Gd ion to obtain the relative signal intensity (RSI) for each imaging condition. The percent signal enhancement was calculated as follows: $\left(\mathrm{RSI}_{\text {postinjection }} / \mathrm{RSI}_{\text {preinjection }}-1\right) \times 100(\%)$.

Statistical Analysis Statistical analysis of the experimental data was performed using a two-tailed Student's $t$-test with Welch's correction. $p<0.05$ and $p<0.01$ were regarded as 
statistically significant.

\section{RESULTS}

Characterization of NPs The average particle sizes for the NPs, F(2000)-NPs, and F(5000)-NPs were 76.4, 73.2, and $76.0 \mathrm{~nm}$ respectively, with a narrow size distribution (polydispersity index $<0.3)$. The $\zeta$-potential of the NPs, F(2000)-NPs, and $\mathrm{F}(5000)$-NPs were $-2.4,-5.2$, and $-6.8 \mathrm{mV}$, respectively, indicating that these NP had slightly negative charges. The $R_{1}$ values of NPs and $\mathrm{F}(5000)$-NPs were 3.4 and $3.7 \mathrm{~mm}^{-1} \mathrm{~s}^{-1}$, respectively, which were similar to that of Gd-DTPA

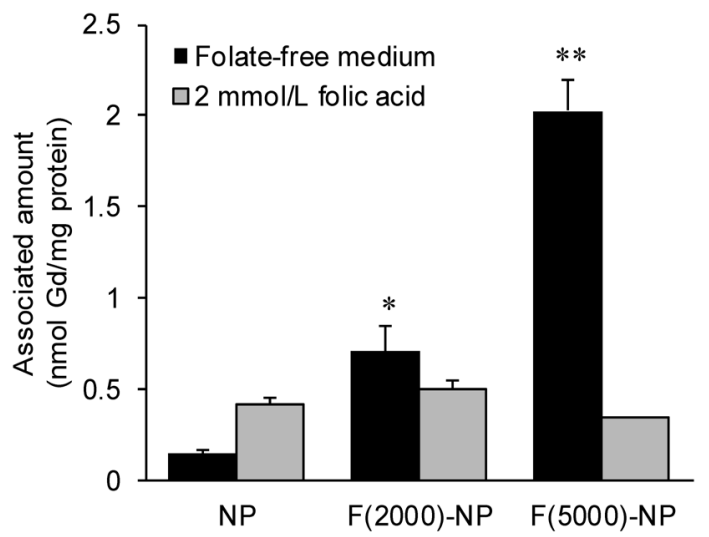

Fig. 1. Cellular Association of NPs with KB Cells in the Absence or Presence of $2 \mathrm{mmol} / \mathrm{L}$ Folic Acid

Cells were incubated with each NP for $24 \mathrm{~h}$ at $37^{\circ} \mathrm{C}$. Each value represents the mean \pm S.D. $(n=3)$. *: $p<0.05$, **: $p<0.01$ vs. NP in folate-free medium.
(4.1 $\left.\mathrm{mm}^{-1} \mathrm{~s}^{-1}\right)$, as measured by the same method. The Gd loading efficiency of each NP formulation was approximately $80 \%$.

Folate Receptor-Mediated Association of Folate-Modified NPs First, to confirm folate receptor-mediated cellular association, folate-modified NPs were incubated with KB cells in vitro. As shown in Fig. 1, the associated amounts of F(2000)-NPs and F(5000)-NPs were 5- and 14-fold greater than that of NPs, respectively. These results correspond well with the idea that conjugating folate to a shorter PEG polymer reduces folate exposure by interfering with the ability of NPs to interact with the folate receptor. ${ }^{34)}$ Furthermore, this increased association of $\mathrm{F}(2000)-\mathrm{NPs}$ and F(5000)-NPs was blocked by the addition of $2 \mathrm{mmol} / \mathrm{L}$ free folic acid to the me-

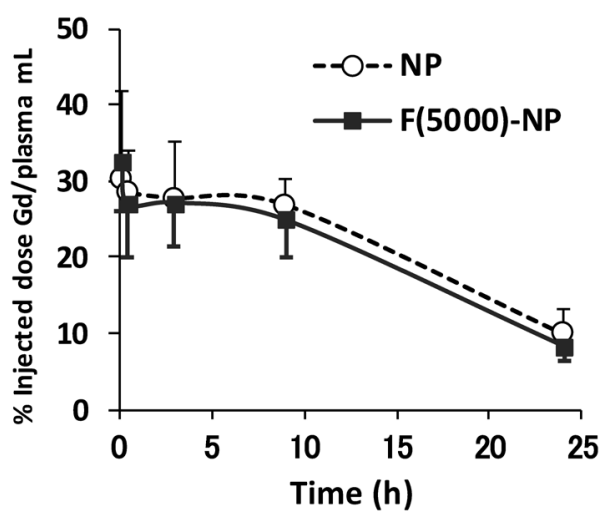

Fig. 2. Blood Concentration Time Curves of NPs and F(5000)-NPs in BALB/c Nude Mice at a Dose of $0.2 \mathrm{mmol} \mathrm{Gd} / \mathrm{kg}$

Each value represents the mean \pm S.D. $(n=3)$.

\section{a}
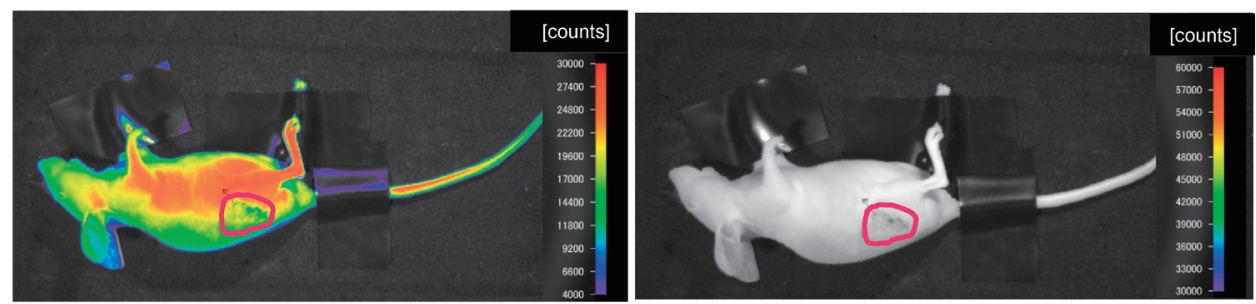

\section{b}
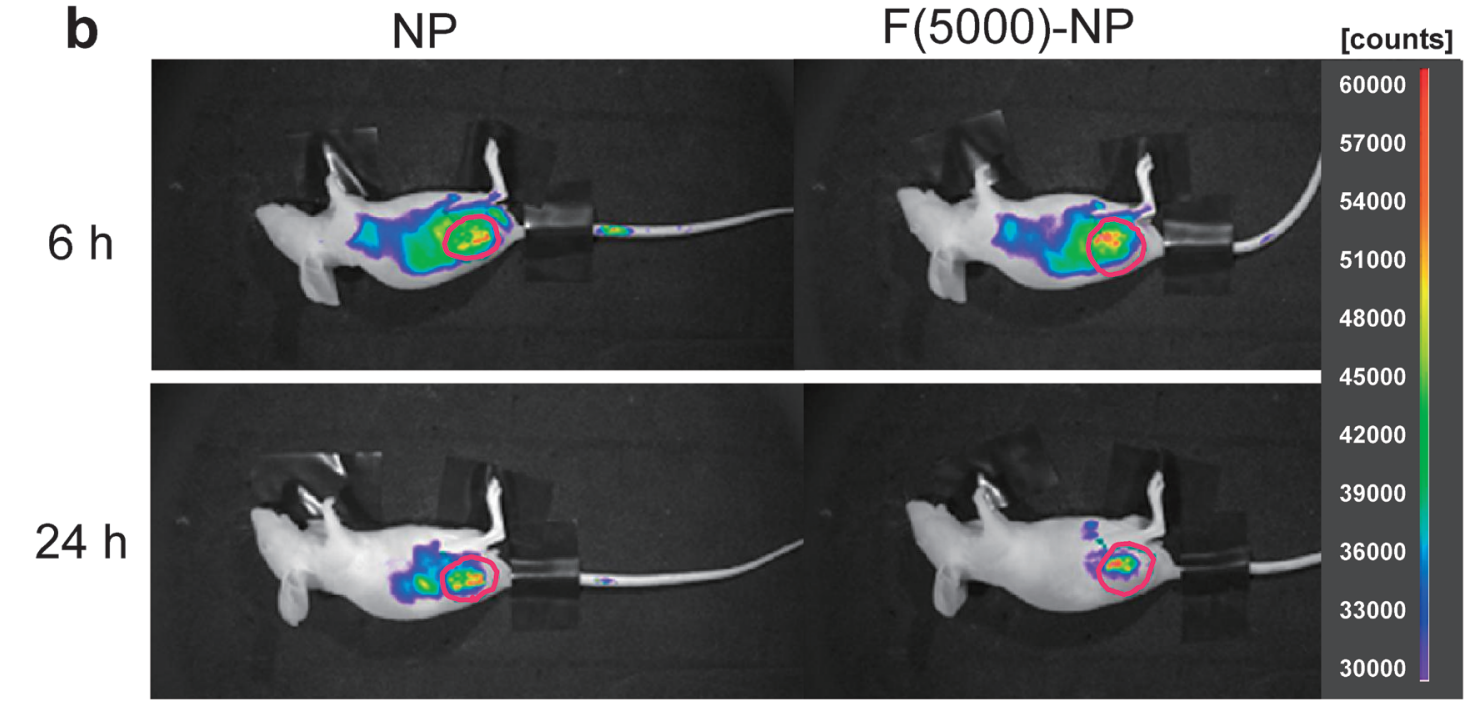

[counts]

Fig. 3. In Vivo Fluorescence Images of BALB/c Nude Mice Bearing KB Tumor

(a) The untreated mouse showed emitted fluorescence within the range of 4000-30000 counts (left) and 30000-60000 counts (right). (b) In vivo fluorescence images of mice injected with NP or F(5000)-NP $(0.2 \mathrm{mmol} \mathrm{Gd} / \mathrm{kg})$ at $6 \mathrm{~h}$ and $24 \mathrm{~h}$. Red circles indicate the tumor position. 
dium, indicating that the association of these NPs was folate receptor-mediated. In the following experiments, F(5000)-NPs, which exhibited higher cellular association than F(2000)-NPs, were used as folate-modified NPs and compared with NPs.

Blood Circulation Stability of Folate-Modified NPs Second, the stability of NPs in the bloodstream was evaluated because it was reported that folate-modified NPs were cleared faster from the circulation. ${ }^{27)}$ Figure 2 shows the blood concentration time course of the NPs until $24 \mathrm{~h}$ after the injection of NPs or F(5000)-NPs. At $24 \mathrm{~h}$ after their injection, 9.8 \pm 3.4 and $8.3 \pm 1.9 \%$ (mean \pm S.D.) of the injected dose of NPs and $\mathrm{F}(5000)-N P s$ remained in the blood, respectively. These high blood concentrations confirm the prolonged circulation of the NPs in blood. This property of prolonged circulation of NPs was expected to lead to high tumor accumulation via the EPR effect as well as folate targeting.

In Vivo Fluorescence Imaging with Cy7-Labeled FolateModified NPs Near-infrared fluorescence images of KB tumor-bearing nude mice were acquired 6 and $24 \mathrm{~h}$ after the intravenous injection of Cy7-labeled NPs and F(5000)-NPs (Fig. 3). The maximum autofluorescence observed in the untreated mouse was 30000 counts (Fig. 3a); fluorescence emitted above 30000 counts was determined to be specific to NPs (Fig. 3b). These NPs were distributed in broad areas of mice $6 \mathrm{~h}$ after their injection and were more localized around the tumor $24 \mathrm{~h}$ after their injection. In particular, F(5000)-NPs exhibited selective accumulation in the tumor, which was expected to permit differentiation of the tumor from other tissues. Therefore, we evaluated Gd biodistribution and MRI signal enhancement $24 \mathrm{~h}$ after NP injection in the following experiments. a

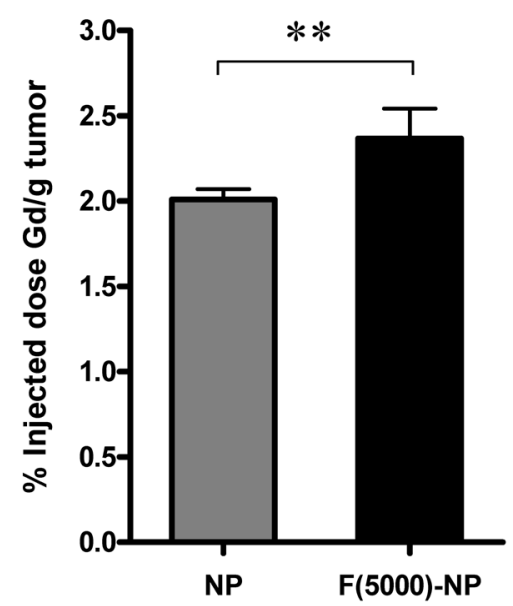

b

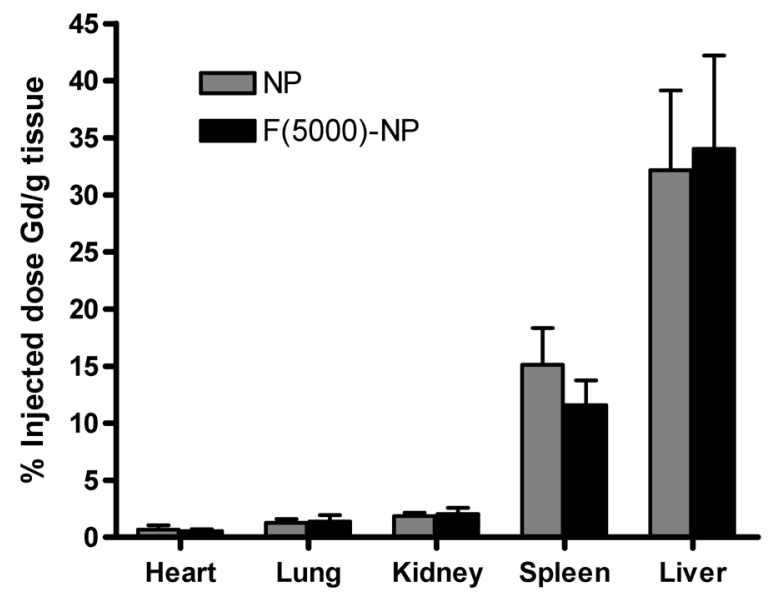

Fig. 4. Distribution of Gd in the Tumor (a) and Other Organs (b) $24 \mathrm{~h}$ after the Intravenous Injection of NPs or F(5000)-NPs $(0.2 \mathrm{mmol} \mathrm{Gd} / \mathrm{kg}$ ) into BALB/c Nude Mice Bearing KB Tumors

Each value represents the mean \pm S.D. $(n=4)$. **: $p<0.01$.

a

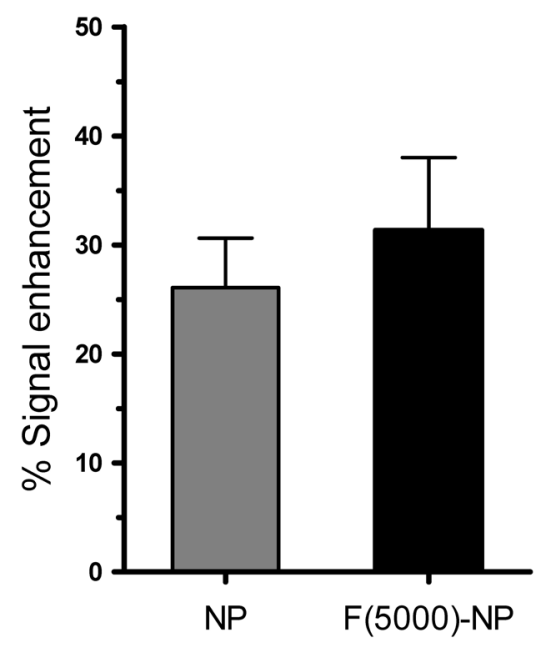

b
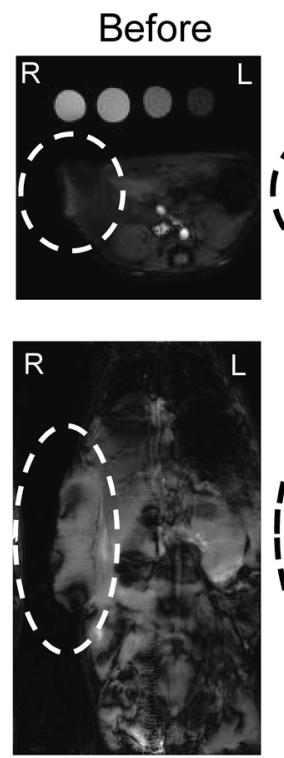

$24 \mathrm{~h}$
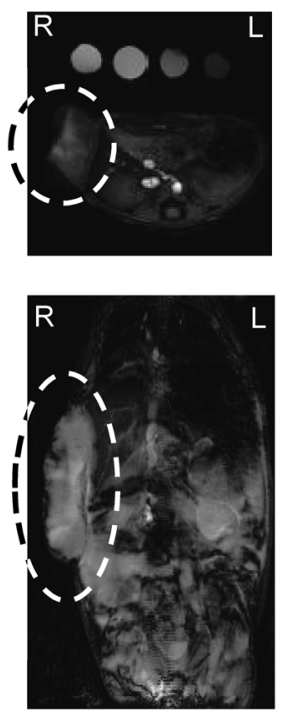

Fig. 5. Percentage of Signal Intensity Enhancement Relative to Preinjection $T_{1}$-Weighted MR Images (a) and Axial and Coronal Slices of BALB/c Nude Mice Bearing KB Tumors before and $24 \mathrm{~h}$ after the Intravenous Injection of F(5000)-NPs $(0.2 \mathrm{mmol} \mathrm{Gd} / \mathrm{kg})(\mathrm{b})$

Each value in (a) represents the mean \pm S.D. $(n=4)$. 
Biodistribution of Folate-Modified NPs The biodistribution of the NP contrast agents was evaluated in BALB/c nude mice bearing KB tumors. Figure 4 shows the percentage of the injected Gd dose of the NPs $24 \mathrm{~h}$ after injection in the normal organs and tumor tissues. The accumulation of the NPs and F(5000)-NPs in tumor tissues reached $2.0 \%$ and $2.4 \%$ of the injected dose/g of tumor, respectively. Folate modification significantly increased the amount of accumulated NPs by 1.2 -fold $(p<0.01)$. This result indicated that the NPs were moderately targeted to the solid tumors. Furthermore, tumor Gd delivery was observed in conjunction with low accumulation in the heart, lungs, and kidneys. For the mononuclear phagocyte system, the accumulation of NPs and F(5000)-NPs reached $15.1 \%$ and $11.6 \%$ of the injected dose/g of liver and $32.2 \%$ and $34.0 \%$ of the injected dose/g of spleen, respectively. The large discrepancy in the distribution pattern between fluorescence image and $\mathrm{Gd}$ amount may be due to poor tissue penetration of fluorescence from the deeper regions, despite the near-infrared dye used.

MRI of Tumor Tissue $T_{1}$-Weighted MR images of tumor tissues were observed before and $24 \mathrm{~h}$ after NP injection in the KB tumor-bearing mice (Fig. 5). Even at $24 \mathrm{~h}$ after injection, an intense signal was observed in the heart and aortic areas (data not shown). This indicated that a considerable amount of the contrast agent was circulating in the bloodstream, as described by the pharmacokinetic results. Figure 5A shows the RSI in axial slices of the tumor tissues $24 \mathrm{~h}$ after NP and $\mathrm{F}(5000)-\mathrm{NP}$ injection. The RSI was increased by $26 \%$ and $31 \%$ by NP and $\mathrm{F}(5000)-\mathrm{NP}$ injection compared with the preinjection signal, respectively. As shown in Fig. 5B, the signal intensity of the tumor area had gradually increased by $24 \mathrm{~h}$. These results indicated that the enhancement of MR signals in the tumor area was the result of the successful active accumulation of F(5000)-NPs in solid tumors.

\section{DISCUSSION}

Previously, it was reported that folate-modified liposomes should exhibit prolonged circulation in the bloodstream, as their accumulation in tumors was attenuated due to the accelerated clearance of ligand-modified formulations before reaching cancer cells expressing the folate receptor. ${ }^{29)}$ In the present study, we developed a nanoparticulate contrast agent with both long blood circulation and folate-targeting characteristics, and we successfully observed the enhancement of MRI signals in the tumor area.

First, we prepared a PEG-micelle contrast agent composed of Gd-DTPA-BSA and $\mathrm{PEG}_{2000}$-DSPE that was reported to enhance the atherosclerotic plaque signal via tyrosine modification. ${ }^{32,35)}$ However, because this micelle had a highly negative charge (approximately $-40 \mathrm{mV}$ ), it mostly accumulated in the liver and spleen (data not shown). This finding corresponded with the report that the accumulation of NPs with highly negative charges in the liver and spleen was higher than that of NPs with neutral charges. ${ }^{37)}$ Therefore, because nanoparticulate contrast agents with highly negative charges were not suitable for tumor targeting based on the EPR effect, a cationic cholesterol derivative (DC-Chol) was added to the formulation to neutralize the negative surface charge. Surface charge-modulated NPs exhibited prolonged blood circulation compared with original PEG-micelle $\left(t_{1 / 2}=1.5-2.0 \mathrm{~h}^{38,39)}\right)$, and approximately $10 \%$ of the injected dose was retained $24 \mathrm{~h}$ after injection (Fig. 2), and less accumulation was observed in the liver and spleen (Fig. 4) irrespective of folate modification. Additionally, since addition of cholesterol to PEG-lipid micelles reduced core lipid mobility, ${ }^{33)}$ increment of core rigidness of NP by DC-Chol might prevent their dissociation and enhance blood retention. Further stabilization of NPs in circulation may enhance their accumulation in tumors via the EPR effect. ${ }^{27)}$

For the folate receptor targeting, NPs modified with a sufficiently long PEG chain exhibited the highest association in KB cells, which overexpress the folate receptor, and this association was inhibited by the addition of free folic acid (Fig. 1). These results suggested that in $\mathrm{F}(2000)-\mathrm{NPs}$, steric hindrance of the PEG chains of the NP composition interfered with folate receptor recognition, whereas in $\mathrm{F}(5000)-\mathrm{NPs}$, there were no obstacles to this interaction. Furthermore, increased flexibility of folate by extension of long PEG chains may facilitate enhanced accessibility of the ligand to the cell surface receptor. These in vitro findings were consistent with the findings of previous reports on the receptor-dependent cellular uptake of folate-modified liposomes, ${ }^{28,34)}$ polymeric micelles, ${ }^{40)}$ and superparamagnetic iron oxide nanoparticles. ${ }^{41}$ )

Conversely, surface modification by ligands accelerated NP clearance by increased accumulation in the liver, resulting in attenuated EPR effect-mediated accumulation in tumors. ${ }^{27)}$ Indeed, the amount of folate-modified liposomes accumulated in the tumor was equal or less than the amount of unmodified liposomes accumulated in the tumor. ${ }^{27,42)}$ The finding from in vivo fluorescence imaging seemed to be faster tumor accumulation of $\mathrm{F}(5000)-\mathrm{NPs}$ than that of NPs (Fig. 3 ) and the accumulation amount was 1.2 times increased by folate modification (Fig. 4). However, F(5000)-NPs had a similar pharmacokinetic profile and tissue distribution as NPs except tumor (Figs. 2, 4). The reason of this difference is not clear at present. These in vivo findings were consisted with recent report that folate-targeted docetaxel-lipid-basednanosuspensions (LNS) exhibited higher antitumor efficacy and 1.13 times higher tumor accumulation, but similar longcirculation compared with non-targeted PEGylated LNS postinjection. ${ }^{43)}$ In this study, the protective effect of the outer shell of PEG chains increased the stability of NPs in blood and prolonged the blood circulation of Gd, probably because NPs have a higher PEG density than liposomes; i.e., NPs contained approximately $40 \mathrm{~mol} \%$ PEG-lipid, whereas PEGylated liposomes contained approximately $5 \mathrm{~mol} \%$ PEG-lipid. ${ }^{44)}$ The characteristics of $\mathrm{F}(5000)$-NPs would be effective for attaining both folate targeting and enhanced accumulation in tumors via the EPR effect.

The accumulated amount of $\mathrm{F}(5000)-\mathrm{NPs}$ in tumor tissue was 1.2-fold higher than that of NP (Fig. 4), and F(5000)-NPs increased tumor signal intensity by $30 \%$ at $24 \mathrm{~h}$ after injection (Fig. 5). Our results were consistent with those of previous reports in which $0.1-0.5 \mathrm{~mol} \%$ of folate modification was effective for folate receptor targeting. ${ }^{28,43,45-47)}$ On the other hand, the liposomal MR contrast agent modified with $3 \mathrm{~mol} \%$ folate$\mathrm{PEG}_{2000}$-DSPE and $4 \mathrm{~mol} \% \mathrm{PEG}_{2000}$-DSPE showed $65 \%$ tumor signal enhancement $2 \mathrm{~h}$ post-injection with 24 -h sustainment post injection. ${ }^{26)}$ It was suggested that ligand density and/or a combination of coated PEG length and folate-modified PEG length might influence the tumor accumulation rate. Further 
optimization of folate modification could potentially improve in vivo targeting of NPs.

Our nanoparticulate contrast agent had almost similar relaxivity as Gd-DTPA; i.e., a low-molecular-weight chelate, and its relaxivity was not significantly altered by folate modification. The macromolecule or nanoparticulate MR contrast agents exhibited higher relaxivity owing to the slow tumbling of the macromolecules compared with that of low-molecularweight chelates. ${ }^{2,48)}$ In the in vivo MRI study, signal enhancement of $T_{1}$-weighted images of the tumor area was observed $24 \mathrm{~h}$ after both NP and F(5000)-NP injection. Therefore, signal enhancement in tumor tissue would be facilitated by the high Gd concentration delivered by NPs to the tumor tissue.

After recognition by the folate receptor, folate-modified NPs were internalized via endocytosis. The internalization of paramagnetic NPs into cells was believed to limit the attainable relaxation enhancement as a consequence of the reduced water exchange across the barriers among the cellular compartments. ${ }^{49)}$ However, F(5000)-NPs exhibited a higher 24-h postinjection/preinjection signal intensity enhancement ratio in tumors than that exhibited by NPs (Fig. 5). Consequently, the significant increase of tumor accumulation due to folate modification might cover the signal attenuation via receptormediated internalization by tumor cells, resulting in tumor signal enhancement.

In conclusion, we successfully delivered folate-modified NPs to tumor tissues and visualized their accumulation by MRI and in vivo fluorescence imaging. These results provide an opportunity to develop folate targeting-based imaging applications.

Acknowledgments This work was supported in part by Grants from the Ministry of Education, Culture, Sports, Science and Technology of Japan, and the Science Research Promotion Fund from the Promotion and Mutual Aid Corporation for Private Schools of Japan.

\section{REFERENCES}

1) Ogan MD, Schmiedl U, Moseley ME, Grodd W, Paajanen H, Brasch RC. Albumin labeled with Gd-DTPA. An intravascular contrastenhancing agent for magnetic resonance blood pool imaging: preparation and characterization. Invest. Radiol., 22, 665-671 (1987).

2) Kobayashi H, Brechbiel MW. Nano-sized MRI contrast agents with dendrimer cores. Adv. Drug Deliv. Rev., 57, 2271-2286 (2005).

3) Desser TS, Rubin DL, Muller HH, Qing F, Khodor S, Zanazzi G, Young SW, Ladd DL, Wellons JA, Kellar KE, Toner JL, Snow RA. Dynamics of tumor imaging with Gd-DTPA-polyethylene glycol polymers: dependence on molecular weight. J. Magn. Reson. Imaging, 4, 467-472 (1994).

4) Vexler VS, Clement O, Schmitt-Willich H, Brasch RC. Effect of varying the molecular weight of the MR contrast agent Gd-DTPApolylysine on blood pharmacokinetics and enhancement patterns. $J$. Magn. Reson. Imaging, 4, 381-388 (1994).

5) Ye F, Ke T, Jeong EK, Wang X, Sun Y, Johnson M, Lu ZR. Noninvasive visualization of in vivo drug delivery of poly(L-glutamic acid) using contrast-enhanced MRI. Mol. Pharm., 3, 507-515 (2006).

6) Ayyagari AL, Zhang X, Ghaghada KB, Annapragada A, Hu X, Bellamkonda RV. Long-circulating liposomal contrast agents for magnetic resonance imaging. Magn. Reson. Med., 55, 1023-1029 (2006).

7) Minowa T, Kawano K, Kuribayashi H, Shiraishi K, Sugino T, Hat- tori Y, Yokoyama M, Maitani Y. Increase in tumour permeability following TGF-beta type I receptor-inhibitor treatment observed by dynamic contrast-enhanced MRI. Br. J. Cancer, 101, 1884-1890 (2009).

8) de Smet M, Heijman E, Langereis S, Hijnen NM, Grull H. Magnetic resonance imaging of high intensity focused ultrasound mediated drug delivery from temperature-sensitive liposomes: an in vivo proof-of-concept study. J. Control. Release, 150, 102-110 (2011).

9) Torchilin VP. PEG-based micelles as carriers of contrast agents for different imaging modalities. Adv. Drug Deliv. Rev., 54, 235-252 (2002).

10) Nakamura E, Makino K, Okano T, Yamamoto T, Yokoyama M. A polymeric micelle MRI contrast agent with changeable relaxivity. $J$. Control. Release, 114, 325-333 (2006).

11) Shiraishi K, Kawano K, Minowa $T$, Maitani Y, Yokoyama M. Preparation and in vivo imaging of PEG-poly(L-lysine)-based polymeric micelle MRI contrast agents. J. Control. Release, 136, 14-20 (2009).

12) Matsumura $Y$, Maeda H. A new concept for macromolecular therapeutics in cancer chemotherapy: mechanism of tumoritropic accumulation of proteins and the antitumor agent smancs. Cancer Res., 46, 6387-6392 (1986).

13) Maeda $\mathrm{H}, \mathrm{Wu} J$, Sawa $\mathrm{T}$, Matsumura $\mathrm{Y}$, Hori K. Tumor vascular permeability and the EPR effect in macromolecular therapeutics: a review. J. Control. Release, 65, 271-284 (2000).

14) Högemann-Savellano D, Bos E, Blondet C, Sato F, Abe T, Josephson L, Weissleder R, Gaudet J, Sgroi D, Peters PJ, Basilion JP. The transferrin receptor: a potential molecular imaging marker for human cancer. Neoplasia, 5, 495-506 (2003).

15) Mulder WJ, Strijkers GJ, Habets JW, Bleeker EJ, van der Schaft DW, Storm G, Koning GA, Griffioen AW, Nicolay K. MR molecular imaging and fluorescence microscopy for identification of activated tumor endothelium using a bimodal lipidic nanoparticle. FASEB J., 19, 2008-2010 (2005).

16) Pirollo KF, Dagata J, Wang P, Freedman M, Vladar A, Fricke S, Ileva L, Zhou Q, Chang EH. A tumor-targeted nanodelivery system to improve early MRI detection of cancer. Mol. Imaging, 5, 41-52 (2006).

17) Erdogan S, Medarova ZO, Roby A, Moore A, Torchilin VP. Enhanced tumor MR imaging with gadolinium-loaded polychelating polymer-containing tumor-targeted liposomes. J. Magn. Reson. Imaging, 27, 574-580 (2008).

18) Wu M, Gunning W, Ratnam M. Expression of folate receptor type alpha in relation to cell type, malignancy, and differentiation in ovary, uterus, and cervix. Cancer Epidemiol. Biomarkers Prev., 8, 775-782 (1999).

19) Parker N, Turk MJ, Westrick E, Lewis JD, Low PS, Leamon CP. Folate receptor expression in carcinomas and normal tissues determined by a quantitative radioligand binding assay. Anal. Biochem., 338, 284-293 (2005).

20) Corot C, Robert P, Lancelot E, Prigent P, Ballet S, Guilbert I, Raynaud JS, Raynal I, Port M. Tumor imaging using P866, a highrelaxivity gadolinium chelate designed for folate receptor targeting. Magn. Reson. Med., 60, 1337-1346 (2008).

21) Konda SD, Aref M, Brechbiel M, Wiener EC. Development of a tumor-targeting MR contrast agent using the high-affinity folate receptor: work in progress. Invest. Radiol., 35, 50-57 (2000).

22) Chen WT, Thirumalai D, Shih TT, Chen RC, Tu SY, Lin CI, Yang PC. Dynamic contrast-enhanced folate-receptor-targeted MR imaging using a Gd-loaded PEG-dendrimer-folate conjugate in a mouse xenograft tumor model. Mol. Imaging Biol., 12, 145-154 (2010).

23) Sun C, Sze R, Zhang M. Folic acid-PEG conjugated superparamagnetic nanoparticles for targeted cellular uptake and detection by MRI. J. Biomed. Mater. Res. A, 78, 550-557 (2006).

24) Wang ZJ, Boddington S, Wendland M, Meier R, Corot C, DaldrupLink H. MR imaging of ovarian tumors using folate-receptor-target- 
ed contrast agents. Pediatr. Radiol., 38, 529-537 (2008).

25) Meier R, Henning TD, Boddington S, Tavri S, Arora S, Piontek G, Rudelius M, Corot C, Daldrup-Link HE. Breast cancers: MR imaging of folate-receptor expression with the folate-specific nanoparticle P1133. Radiology, 255, 527-535 (2010).

26) Kamaly N, Kalber T, Thanou M, Bell JD, Miller AD. Folate receptor targeted bimodal liposomes for tumor magnetic resonance imaging. Bioconjug. Chem., 20, 648-655 (2009).

27) Gabizon A, Horowitz AT, Goren D, Tzemach D, Shmeeda H, Zalipsky S. In vivo fate of folate-targeted polyethylene-glycol liposomes in tumor-bearing mice. Clin. Cancer Res., 9, 6551-6559 (2003).

28) Shiokawa T, Hattori Y, Kawano K, Ohguchi Y, Kawakami H, Toma $\mathrm{K}$, Maitani Y. Effect of polyethylene glycol linker chain length of folate-linked microemulsions loading aclacinomycin A on targeting ability and antitumor effect in vitro and in vivo. Clin. Cancer Res., 11, 2018-2025 (2005).

29) Yamada A, Taniguchi Y, Kawano K, Honda T, Hattori Y, Maitani Y. Design of folate-linked liposomal doxorubicin to its antitumor effect in mice. Clin. Cancer Res., 14, 8161-8168 (2008).

30) Lukyanov AN, Torchilin VP. Micelles from lipid derivatives of water-soluble polymers as delivery systems for poorly soluble drugs. Adv. Drug Deliv. Rev., 56, 1273-1289 (2004).

31) Mulder WJ, Strijkers GJ, van Tilborg GA, Griffioen AW, Nicolay K. Lipid-based nanoparticles for contrast-enhanced MRI and molecular imaging. NMR Biomed., 19, 142-164 (2006).

32) Mulder WJ, Strijkers GJ, Briley-Saboe KC, Frias JC, Aguinaldo JG, Vucic E, Amirbekian V, Tang C, Chin PT, Nicolay K, Fayad ZA. Molecular imaging of macrophages in atherosclerotic plaques using bimodal PEG-micelles. Magn. Reson. Med., 58, 1164-1170 (2007).

33) Vakil R, Kwon GS. Effect of cholesterol on the release of amphotericin B from PEG-phospholipid micelles. Mol. Pharm., 5, 98-104 (2008).

34) Gabizon A, Horowitz AT, Goren D, Tzemach D, Mandelbaum-Shavit F, Qazen MM, Zalipsky S. Targeting folate receptor with folate linked to extremities of poly(ethylene glycol)-grafted liposomes: in vitro studies. Bioconjug. Chem., 10, 289-298 (1999).

35) Beilvert A, Cormode DP, Chaubet F, Briley-Saebo KC, Mani V, Mulder WJ, Vucic E, Toussaint JF, Letourneur D, Fayad ZA. Tyrosine polyethylene glycol (PEG)-micelle magnetic resonance contrast agent for the detection of lipid rich areas in atherosclerotic plaque. Magn. Reson. Med., 62, 1195-1201 (2009).

36) Shmeeda H, Mak L, Tzemach D, Astrahan P, Tarshish M, Gabizon A. Intracellular uptake and intracavitary targeting of folate-conjugated liposomes in a mouse lymphoma model with up-regulated folate receptors. Mol. Cancer Ther., 5, 818-824 (2006).

37) Li SD, Huang L. Pharmacokinetics and biodistribution of nanoparticles. Mol. Pharm., 5, 496-504 (2008).
38) Lukyanov AN, Gao Z, Mazzola L, Torchilin VP. Polyethylene glycol-diacyllipid micelles demonstrate increased acculumation in subcutaneous tumors in mice. Pharm. Res., 19, 1424-1429 (2002).

39) Briley-Saebo KC, Shaw PX, Mulder WJ, Choi SH, Vucic E, Aguinaldo JG, Witztum JL, Fuster V, Tsimikas S, Fayad ZA. Targeted molecular probes for imaging atherosclerotic lesions with magnetic resonance using antibodies that recognize oxidation-specific epitopes. Circulation, 117, 3206-3215 (2008).

40) Hayama A, Yamamoto T, Yokoyama M, Kawano K, Hattori Y, Maitani Y. Polymeric micelles modified by folate-PEG-lipid for targeted drug delivery to cancer cells in vitro. J. Nanosci. Nanotechnol., 8 , 3085-3090 (2008).

41) Kaaki K, Herve-Aubert K, Chiper M, Shkilnyy A, Souce M, Benoit R, Paillard A, Dubois P, Saboungi ML, Chourpa I. Magnetic nanocarriers of doxorubicin coated with poly(ethylene glycol) and folic acid: relation between coating structure, surface properties, colloidal stability, and cancer cell targeting. Langmuir, 28, 1496-1505 (2012).

42) Leamon CP, Cooper SR, Hardee GE. Folate-liposome-mediated antisense oligodeoxynucleotide targeting to cancer cells: evaluation in vitro and in vivo. Bioconjug. Chem., 14, 738-747 (2003).

43) Wang L, Li M, Zhang N. Folate-targeted docetaxel-lipid-basednanosuspensions for active-targeted cancer therapy. Int. J. Nanomedicine, 7, 3281-3294 (2012).

44) Allen TM, Hansen C, Martin F, Redemann C, Yau-Young A. Liposomes containing synthetic lipid derivatives of poly(ethylene glycol) show prolonged circulation half-lives in vivo. Biochim. Biophys. Acta, 1066, 29-36 (1991).

45) Lee RJ, Low PS. Folate-mediated tumor cell targeting of liposomeentrapped doxorubicin in vitro. Biochim. Biophys. Acta, 1233, 134-144 (1995)

46) Goren D, Horowitz AT, Tzemach D, Tarshish M, Zalipsky S, Gabizon A. Nuclear delivery of doxorubicin via folate-targeted liposomes with bypass of multidrug-resistance efflux pump. Clin. Cancer Res., 6, 1949-1957 (2000).

47) Pan XQ, Wang H, Lee RJ. Antitumor activity of folate receptortargeted liposomal doxorubicin in a $\mathrm{KB}$ oral carcinoma murine xenograft model. Pharm. Res., 20, 417-422 (2003).

48) Wang Y, Ye F, Jeong EK, Sun Y, Parker DL, Lu ZR. Noninvasive visualization of pharmacokinetics, biodistribution and tumor targeting of poly[ $N$-(2-hydroxypropyl)methacrylamide] in mice using contrast enhanced MRI. Pharm. Res., 24, 1208-1216 (2007).

49) Grange C, Geninatti-Crich S, Esposito G, Alberti D, Tei L, Bussolati B, Aime S, Camussi G. Combined delivery and magnetic resonance imaging of neural cell adhesion molecule-targeted doxorubicin-containing liposomes in experimentally induced Kaposi's sarcoma. Cancer Res., 70, 2180-2190 (2010). 